\title{
A study of antenatal anxiety: comparison across trimesters
}

\author{
Krishna Priyambada ${ }^{1}$, Amrit Pattojoshi² ${ }^{2}$ Ajay K. Bakhla ${ }^{3 *}$
}

\begin{abstract}
${ }^{1}$ Department of Obstetrics and Gynaecology, Kalinga Institute of Medical Science, Bhubaneshwar, Orissa, India ${ }^{2}$ Department of Psychiatry, Hi-Tech Medical College and Hospital, Bhubaneshwar, Orissa, India

${ }^{3}$ Department of Psychiatry, Rajendra Institute of Medical Sciences, Ranchi, Jharkhand, India
\end{abstract}

Received: 23 March 2017

Accepted: 28 March 2017

\author{
*Correspondence: \\ Dr. Ajay K. Bakhla, \\ E-mail: ajaybakhla@gmail.com
}

Copyright: () the author(s), publisher and licensee Medip Academy. This is an open-access article distributed under the terms of the Creative Commons Attribution Non-Commercial License, which permits unrestricted non-commercial use, distribution, and reproduction in any medium, provided the original work is properly cited.

\begin{abstract}
Background: The aim of present study was to investigate the antenatal anxiety across all three trimesters of pregnancy.

Methods: This is a cross sectional, observational study for which data is collected from consenting subjects attending antenatal Out Patients department for routine antenatal checkup. Data included socio demographic information's and Hospital Anxiety and Depression Scale and statistical analysis done.

Results: Out of 169 Pregnant females $27.8 \%$ were during first trimester, $40.8 \%$ during second trimester and $31.4 \%$ during $3^{\text {rd }}$ trimester. The mean anxiety scores for first, second and third trimester was $10.74 \pm 2.97,11.69 \pm 3.09$ and $14.20 \pm 3.10$ respectively. Independent $t$ test revealed significantly higher anxiety scores for third trimester when compared to first trimester scores $(t=-6.035, \mathrm{p}$ value $=0.000)$.

Conclusions: This study finds a significantly higher antenatal anxiety during third trimester of pregnancy.
\end{abstract}

Keywords: Antenatal anxiety, Pregnancy, Trimester

\section{INTRODUCTION}

Pregnancy and delivery bring many physiological and psychosocial changes and increased vulnerability for the onset or relapse of a mental illness, anxiety disorders are two to three times more common among pregnant women in compared to general population. ${ }^{1,2}$

Depression and anxiety have been linked to somatic complaints, gestational and obstetric complications, stillbirth, premature birth, low birth weight, low Apgar scores, smaller head circumference, alterations in fetal motor activity, affected fetal heart rate patterns and major congenital anomalies. ${ }^{3-8}$ Some studies found the prevalence of similar antenatal anxiety across all three trimesters, but many Previous studies reported that antenatal anxiety varied at different trimesters of pregnancy and high anxiety was found during first and third trimester. ${ }^{9-12}$

Hence antenatal anxiety across trimesters can be of differing severity and different types of anxiety that may have differing consequences as morbidity. we planned this study to compare the differing severity of antenatal anxiety across all three trimesters of pregnancy.

\section{METHODS}

The aim of the present study was to compare the antenatal anxiety across all three trimesters of the pregnancy. This study was conducted at Hi-Tech Medical College and Hospital, Bhubaneshwar, India which is a tertiary care medical college hospital. The study protocol was approved by the institutional review board of HiTech Medical College and Hospital, Bhubaneshwar, 
India. This study is a part of hospital survey for the prevalence of antenatal anxiety and depression, published earlier. ${ }^{13}$ It was a cross-sectional study carried out over a three-month period (November 2016 - January 2017). All adult elective ANC patients who satisfied the inclusion criteria for the study and consented were recruited. All recruited patients were requested to complete a questionnaire about their socio-demographic data sheet and thereafter Hospital Anxiety and Depression Scale (HADS). ${ }^{14}$ was applied, for this present study we utilize only anxiety subset of HADS.

\section{Subjects}

All consenting pregnant women visiting Obstetrics and Gynecology out patient's department (OPD) for Ante Natal Checkups, were included for this study. Exclusion criteria were presence of any major co morbid medical or other illness. Patients were examined clinically after taking detailed history and their socio demographic variables.

\section{Tools}

Socio-demographic Data Sheet: The socio demographic data sheet included age, religion, occupation, education and clinical information like duration of pregnancy and other obstetric history.

\section{Hospital anxiety and depression scale (HADS)}

This is very well validated scale to assess anxiety and depression among hospital based patients. It consists 14 questions, 7 scoring anxiety and 7 scoring depression. Patients were asked to read each question and place a tick against the reply that came closest to how they had been feeling that day. Each answer was scored 0, 1, 2 or 3. The possible range of scores was therefore 0 to 21 , with higher scores indicating greater levels of anxiety. Score of 0-7 is considered normal, scores of $8-10$ is borderline abnormal and scores of $11-21$ is abnormal case. ${ }^{14}$

\section{Procedure}

It was a cross sectional observational study. All subjects were assessed for inclusion-exclusion criteria, and on qualification they were requested to fill up Sociodemographic data sheet or asked verbally and filled up by investigators. The HADS was applied on all subjects and recorded. Only the anxiety subset of HADS was taken into consideration for this study.

\section{Statistical analysis}

The collected data of all subjects was statistically analyzed, using Statistical Package for Social Sciences (SPSS, Inc., Chicago, Illinois) version 10.0.

Data analysis included means and standard deviations for complete sample. The complete sample was categorized as trimester first, second and third as per the duration of pregnancy. Data analysis included means and standard deviations for each trimester. The parametric t-test was used to determine if differences existed between the groups. Statistically significant levels are reported for $p$ values less than or equal to 0.05 . Highly significant levels are $\mathrm{p}$ values less than .001 .

\section{RESULTS}

A total of 169 subjects were included for the study, Table 1 summarizes the sample characteristics. The mean age of the sample was 25.48 years $( \pm 4.64$ years $)$ with minimum age of 18 years to a maximum age of 32 years in ours sample. the mean education years for the sample was found to be $10.37 \pm 2.61$.

Most of the sample was during second trimester $40.8 \%$, followed by 3 rd trimester $31.4 \%$ and 1 st trimester was $27.8 \%$. However, the mean duration of pregnancy for the sample was found to be $17.42 \pm 6.80$ weeks. (Table 1).

\section{Table 1: Sample characteristics and findings.}

\begin{tabular}{|c|c|c|c|}
\hline Total $n=169$ & Min & Max & Mean+SD \\
\hline Age & 18 & 32 & $25.48 \pm 4.64$ \\
\hline $\begin{array}{l}\text { years of } \\
\text { education }\end{array}$ & 5 & 15 & $10.37 \pm 2.61$ \\
\hline \multirow[t]{2}{*}{$\begin{array}{l}\text { duration of } \\
\text { pregnancy } \\
\text { (weeks) }\end{array}$} & 8 & 36 & $17.42 \pm 6.80$ \\
\hline & & n & $\%$ \\
\hline \multirow{2}{*}{ Religion } & Hindu & 128 & 75.7 \\
\hline & Others & 41 & 24.3 \\
\hline \multirow{2}{*}{ occupation } & House wives & 113 & 66.9 \\
\hline & Working & 56 & 33.1 \\
\hline \multirow{2}{*}{ gravida } & Primi gravida & 60 & 35.5 \\
\hline & Poly gravida & 109 & 64.5 \\
\hline \multirow{2}{*}{$\begin{array}{l}\text { history of } \\
\text { abortion }\end{array}$} & Absent & 137 & 81.1 \\
\hline & Present & 32 & 18.9 \\
\hline
\end{tabular}

Table 2. Comparison of mean anxiety scores across three trimesters of pregnancy.

\begin{tabular}{|c|c|c|c|c|}
\hline & $\begin{array}{l}\text { Mean } \\
\text { HADS } \\
\text { anxiety } \\
\text { subscale }\end{array}$ & $\mathrm{t}$ & DF & $\begin{array}{l}\text { Sig. (2- } \\
\text { tailed) } \\
\text { p value }\end{array}$ \\
\hline $\begin{array}{l}1^{\text {st }} \text { Trimester } \\
(\mathrm{n}=47)\end{array}$ & $10.74 \pm 2.97$ & \multirow{2}{*}{-1.714} & \multirow[b]{2}{*}{114} & \multirow[b]{2}{*}{0.089} \\
\hline $\begin{array}{l}2^{\text {nd }} \text { Trimester } \\
(n=69)\end{array}$ & $11.69 \pm 3.09$ & & & \\
\hline $\begin{array}{l}1^{\text {st }} \text { Trimester } \\
(\mathrm{n}=47)\end{array}$ & $10.74 \pm 2.97$ & \multirow{2}{*}{-6.035} & \multirow{2}{*}{97.40} & \multirow{2}{*}{0.000} \\
\hline $\begin{array}{l}3^{\text {nd }} \text { Trimester } \\
(n=53)\end{array}$ & $14.20 \pm 3.10$ & & & \\
\hline
\end{tabular}

On comparing mean anxiety scores of first trimester and second trimester, there was no significant difference $10.74 \pm 2.97$ and $11.69 \pm 3.09$ respectively $(t=-1.714, p$ 
value $=.089)$. (Table 2$)$. When we compared mean anxiety scores of first trimester and third trimester, we found significantly higher anxiety scores for third trimester $(10.74 \pm 2.97$ and $14.20 \pm 3.10$ respectively $(\mathrm{t}=$ $6.035, \mathrm{p}$ value $=0.000)($ Table 2$)$.

\section{DISCUSSION}

This study is a cross sectional prevalence study where we assessed the point prevalence of antenatal anxiety. We included 169 pregnant females with various duration of pregnancy (mean duration of pregnancy was 17.42 \pm 6.80 weeks). Other sample characteristics can be described in terms of mean age of $25.48 \pm 4.64$ years and mean years of education was $10.37 \pm 2.61$ years. We found a very high prevalence of anxiety $28.4 \%$ among ours sample of antenatal clinic. This finding is in collaboration with many other studies reporting antenatal anxiety ranges between $12.2 \%$ to $39 \% .15,16$

The findings of significantly higher antenatal anxiety during third trimester is in agreement with previous reports by Madhavanprabhakaran et al where they found higher third trimester pregnancy-specific anxiety in a large sample of 500 pregnant females. That study used State Trait Anxiety Inventory and Pregnancy-Specific Anxiety Inventory and they also identified young age, nulliparous status and nuclear family as common risk factors of pregnancy-specific anxiety. ${ }^{17}$

Female as a gender is itself susceptible for stress, anxiety and depression, and there may be dread of childbirth are vulnerability for surgical intervention and subsequent psycho-social issues. ${ }^{18}$ In a study adjusted linear regression model for anxiety measured by general anxiety (STAI-trait) was inversely associated with literacy, per capita daily household expenditure on food, and practical support during pregnancy; it was directly associated with poor relationship with husband, physical violence ever, and violence during pregnancy. ${ }^{19}$

There may be various psychosocial factors to neuroendocrinal factors that may contribute to antenatal anxiety during entire period of pregnancy as well as significantly higher anxiety during third trimester of pregnancy. This study lacks to address those possible psychosocial and neuro endocrinal factors involved, present study also limited by its shorter sample size and lack of follow up longitudinal design, which may be corrected in future studies.

\section{CONCLUSION}

This study finds a significantly higher antenatal anxiety during third trimester of pregnancy when compared to first or second trimester of pregnancy.

Funding: No funding sources Conflict of interest: None declared
Ethical approval: The study was approved by the Institutional Ethics Committee

\section{REFERENCES}

1. Smith MV, Shao L, Howell H, Lin H, Yonkers KA. Perinatal depression and birth outcomes in a Healthy Start project. Matern. Child Health J. 2011;15:401-9.

2. Adewuya AO, Ola BA, Aloba OO, Mapayi BM. Anxiety disorders among Nigerian women in late pregnancy: a controlled study. Arch Womens Ment Health. 2006;9:325-8.

3. Marcus SM. Depression during pregnancy: rates, risks and consequences - mother risk Update 2008. Can. J. Clin. Pharmacol. 2009;16:15-22.

4. Kelly RH, Russo J and Katon W. Somatic complaints among pregnant women cared for in obstetrics: Normal pregnancy or depressive and anxiety symptom amplification revisited? General Hospital Psychiatry. 2001;23:107-13.

5. Raisanen S, Lehto SM, Nielsen HS, Gissler M, Kramer MR, Heinonen S. Risk factors for and perinatal outcomes of major depression during pregnancy: a population-based analysis during 2002 2010 in Finland. BMJ Open. 2014;4:004883.

6. Laursen M, Johansen C. and Hedegaard M. Fear of childbirth and risk for birth complications in nulliparous women in the Danish National Birth Cohort. BJOG. 2009;116:1350-5.

7. DiPietro JA, Hilton SC, Hawkins M, Costigan KA. and Pressman EK. Maternal stress and affect influence fetal neurobehavioral development. Develop- mental Psychology. 2002;38:659.

8. Brouwers E, van Baar A and Pop V. Maternal anxiety during pregnancy and subsequent infant development. Infant Behavior and Development. 2001;24:95-106.

9. Teixeira C, Figueiredo B, Conde A, Pacheco A, Costa R. Anxiety and depression during pregnancy in women and men. J. Affect. Disord. 2009;119:1428.

10. Lee AM, Lam SK, Sze Mun Lau SM, Chong CS, Chui HW, Fong DY. Prevalence, course, and risk factors for antenatal anxiety and depression. Obstet. Gynecol. 2007;110:1102-12.

11. Bennett HA, Einarson A, Taddio A, Koren G, Einarson TR. Prevalence of depression during pregnancy: systematic review. Obstet. Gynecol. 2004;103:698-709.

12. Gavin NI, Gaynes BN, Lohr KN, Meltzer-Brody S, Gartlehner G, Swinson T. Perinatal depression: a systematic review of prevalence and incidence. Obstet. Gynecol. 2005;106:1071-83.

13. Priamabada K, Pattojoshi A, Bakhla AK. Prevalence of antenatal anxiety and depression. Paripex Indian Journal of Research. 2017;6(3):107-8.

14. Zigmond AS, Snaith RP. The hospital anxiety and depression scale. Acta Psychiatr Scand. 1983;67:361-70. 
15. Adewuya AO, Ola BA, Aloba OO, Mapayi BM. Anxiety disorders among Nigerian women in late pregnancy: a controlled study. Arch Womens Ment Health. 2006;9:325-8.

16. Goodman JH, Guarino A, Chenausky K, Klein L, Prager J, Petersen R, et al. CALM Pregnancy: results of a pilot study of mindfulness-based cognitive therapy for perinatal anxiety. Arch Womens Ment Health. 2014;17:373-87.

17. Madhavanprabhakaran GK, D'Souza MS, Nairy KS. Prevalence of pregnancy anxiety and associated factors. International Journal of Africa Nursing Sciences. 2015;3:1-7.
18. Patel R, Biros MH, Moore J, Miner JR. Gender differences in patient-described pain, stress, and anxiety among patients undergoing treatment for painful conditions in the emergency department. Acad Emerg Med. 2014:21(12):1478-84.

19. Nasreen HE, Kabir ZN, Forsell Y, Edhborg M. Prevalence and associated factors of depressive and anxiety symptoms during pregnancy: a population based study in rural Bangladesh.BMC Womens Health. 2011;2;11-22.

Cite this article as: Priyambada K, Pattojoshi A, Bakhla AK. A study of antenatal anxiety: comparison across trimesters. Int J Reprod Contracept Obstet Gynecol 2017;6:1810-3. 